
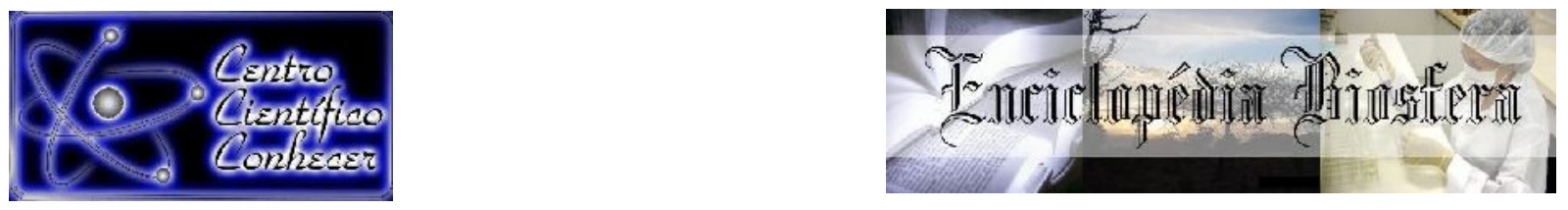

\title{
CONSTRUÇÃO DE UM PROTÓTIPO DE BARCO CONTROLADO À DISTÂNCIA DE BAIXO CUSTO PARA MONITORAMENTO LIMNOLÓGICO EM CORPOS D'ÁGUA RASOS
}

\author{
Marlon Mendes de Oliveira ${ }^{1,2}$, Luciano Resende Dias², Alessandro Luvizon Bergamo, \\ Thiago Luiz Lara Oliveira ${ }^{1}$, Saulo de Tarsio Silva Sousa², \\ 1 Universidade Federal de Itajubá, Mestrado Profissional em Engenharia Hídrica, \\ (UNIFEI). \\ ${ }^{2}$ Instituto Federal Fluminense (IFF). \\ E-mail: oliveira.m.marlon@gmail.com
}
Recebido em: 15/05/2021 - Aprovado em: 15/06/2021 - Publicado em: 30/06/2021
DOI: 10.18677/EnciBio_2021B9

\begin{abstract}
RESUMO
Existem muitas dificuldades para o correto monitoramento de corpos d'água rasos, dentre as maiores dificuldades no estabelecimento dessa rotina de monitoramento é a questão de toda a logística necessária, a qual requer pessoal treinado e o emprego de equipamentos caros, tais como embarcação, motor, meios de transporte para estes equipamentos. Outro fator de complicação é que muitos desses ecossistemas são rasos e não permitem a entrada de embarcações tripuladas. Portanto, este projeto desenvolveu uma embarcação controlada à distância, não tripulada capaz de coletar amostras de água. A embarcação desenvolvida nesse projeto é alimentada por energia solar, sendo controlado por placa de prototipagem eletrônica do tipo Arduino®. $\mathrm{O}$ protótipo desenvolvido contemplou a utilização de tecnologias de baixo custo em seu projeto e montagem, além da utilização de código aberto. O barco robô foi testado em campo, obtendo resultados satisfatórios.
\end{abstract}

PALAVRAS-CHAVE: Arduino, corpos hídricos, embarcação controlada à distância, monitoramento limnológico.

\section{LOW COST BOAT PROTOTYPE CONTROLLED AT A DISTANCE FOR LIMNOLOGY MONITORING IN SHALLOW WATER.}

\section{ABSTRACT}

There are several factors that difficult the monitoring processes of shallow water places, one of the major difficulties for establishing a routine to monitor a water body is cost. Since monitoring a water body or hydrographical system requires advanced equipment and specialized is costly, the acquisition and implementation is prohibitive in many cases, especially for developing countries. Another difficulty is that many of the ecosystems are shallow, making the use of manned vessels impossible. Thus, this study 
developed a vessel remotely controlled, a non-manned vessel that is able to collect water samples. Additionally, the boat is moved through solar energy, the navigation is controlled by Arduino ${ }^{\circledR}$ electronic prototyping boards, the prototype was developed using low cost technologies and does not require specialized personal to assembly and operate, it also uses an open source code. The robot vessel was tested in field, showing satisfactory results.

KEYWORDS: Arduino, Limnology monitoring, remote control of boat vessels, water body/hydrographical system.

\section{INTRODUÇÃO}

As alterações na qualidade da água dos ecossistemas aquáticos podem ser causadas por processos naturais ou antropogênicos. Entre as alterações antropogênicas, a ocupação humana da bacia de drenagem pode causar o assoreamento, o lançamento de efluentes domésticos e resíduos industriais sem tratamento, comprometendo o funcionamento dos ecossistemas aquáticos além de inviabilizar o uso humano (FIA et al., 2015).

O monitoramento limnológico abrange a coleta periódica associada e análise de dados sobre qualidade da água para propósitos de efetivo gerenciamento dos ecossistemas aquáticos, sendo importante incluir um maior número de variáveis para melhor subsidiar a tomada de decisões. Entre as variáveis limnológicas ligas ao uso do solo na bacia de drenagem, destacam-se as concentrações de fósforo, nitrogênio, oxigênio dissolvido e clorofila a, e também os valores de $\mathrm{pH}$, turbidez e densidade de coliformes fecais e totais. Também existe a necessidade integrar os resultados do monitoramento, limnológico a um planejamento do uso do solo e a programas de educação ambiental, os quais venham estimular a participação popular na gestão dos recursos hídricos (MAROTTA et al., 2008).

O monitoramento limnológico abrange a coleta periódica associada e análise de dados sobre qualidade da água para propósitos de efetivo gerenciamento ambiental dos processos industriais, fornece informações permitindo averiguar a eficiência dos equipamentos de controle ambiental, também permite detectar perdas de matériasprimas e produtos, sendo economicamente atrativo para as empresa. Com monitoramento limnológico as empresas aumentam a possibilidade de cumprir a legislação ambiental, pois com a identificação do ambiente em questão e possível planejar medidas mitigadoras minimizando os danos (ESTEVES; ROCHA, 2015).

Uma das maiores dificuldades no estabelecimento da rotina de monitoramento desses ambientes é sua logística; uma alternativa para o monitoramento das variáveis limnológicas em águas rasas é a utilização de robôs. Nas últimas décadas cientistas e engenheiros se concentraram no desenvolvimento de plataformas autônomas de pequeno porte e baixo custo para o monitoramento da qualidade e dados específicos da água com o objetivo de aumentar a taxa de amostragem no espaço e tempo (CHAVEZ et al. 2018).

A resistência dos robôs nas atividades de coleta de dados principalmente nas aplicações marítimas está diretamente ligada à eficiência energética, a maioria dos robôs, para monitoramento atualmente utilizam energia solar através de painéis fotovoltaicos. Os barcos autônomos fazem uso da visão computacional e muitas vezes 
redes neurais artificiais em seus sistemas de navegação e controle (STECCANELLA et al. 2020).

A utilização de barco robô para monitoramento limnológico evita o transporte de colaboradores em barcos e carros, diminuindo sua exposição aos riscos de acidentes, afogamento, exposição a intempéries e riscos ergométricos, além disso, o barco pode sofrer atualizações e alterações para se adaptar a necessidade, como realizar batimetria do fundo do reservatório, acompanhamento de peixes com sonares (FERREIRA et al., 2016).

Microcontroladores podem ser compreendidos como um computador em um único Chip, contendo um processador, memória, periféricos de entrada e de saída, temporizadores, dispositivos de comunicação e circuitos integrados que podem ser programados para realizar algumas funções específicas. São muito utilizados em testes de bancada pela praticidade, podem ser usados para cumprir as funcionalidades de aquisição de dados e para o controle de dispositivos simples (GONZAGA et al., 2019).

O Arduino ${ }^{\circledR}$ é uma plataforma de prototipagem eletrônica Open-Source com linguagem de programação baseada na linguagem Wiring. O hardware do Arduino ${ }^{\circledR}$ é composto por uma placa de prototipagem na qual são construídos os projetos. Já o software é um Ambiente de Desenvolvimento Integrado (IDE), precisando ser executado em um computador, onde é feita a programação ou recuperação dos dados para a placa de prototipagem (DOLINAY, 2016).

A IDE reúne características e ferramentas de apoio para agilizar e principalmente introduzir na programação usuários não familiarizados com o desenvolvimento de software. Os programas conhecidos como sketches, comunicam à placa o que deve ser executado durante o seu funcionamento. A placa de prototipagem Arduino ${ }^{\circledR}$ possui pinos de entrada e saída do microcontrolador utilizados para conectá-lo a outros circuitos ou sensores (TEIXEIRA; PEREIRA, 2019).

\section{MATERIAL E METODOS}

O presente trabalho desenvolveu e construíu um protótipo de embarcação tipo catamarã utilizando uma placa de prototipagem eletrônica Arduino® Uno R3. Foi motivado pela oferta deficiente de equipamentos com baixo custo para coletar amostras em corpos d'água rasos, e pela crescente tendência da exploração sustentável dos recursos ambientais, entre estes o recurso hídrico.

Para dimensionar a estrutura e a potência do sistema de propulsão, adotou-se $10 \mathrm{~kg}$ como capacidade de carga, sendo $8 \mathrm{~kg}$ provenientes dos equipamentos que deverão ser transportados pelo protótipo (bateria, painel solar fotovoltaico, sensores, sistema elétrico) e $2 \mathrm{~kg}$ para cargas extras que possam surgir (DANTAS; WEISS, 2015).

Durante a etapa de construção do barco robô, o software SolidWorks foi utilizado como ferramenta de auxílio para a condução do projeto. A escolha ajudou na otimização do tempo e assertividade da montagem. Com isso, as medidas foram conferidas e ajustadas para que posteriormente fossem confeccionadas as peças em tamanho real (Figura 1). 
FIGURA 1: Dimensões e geometria do protótipo.
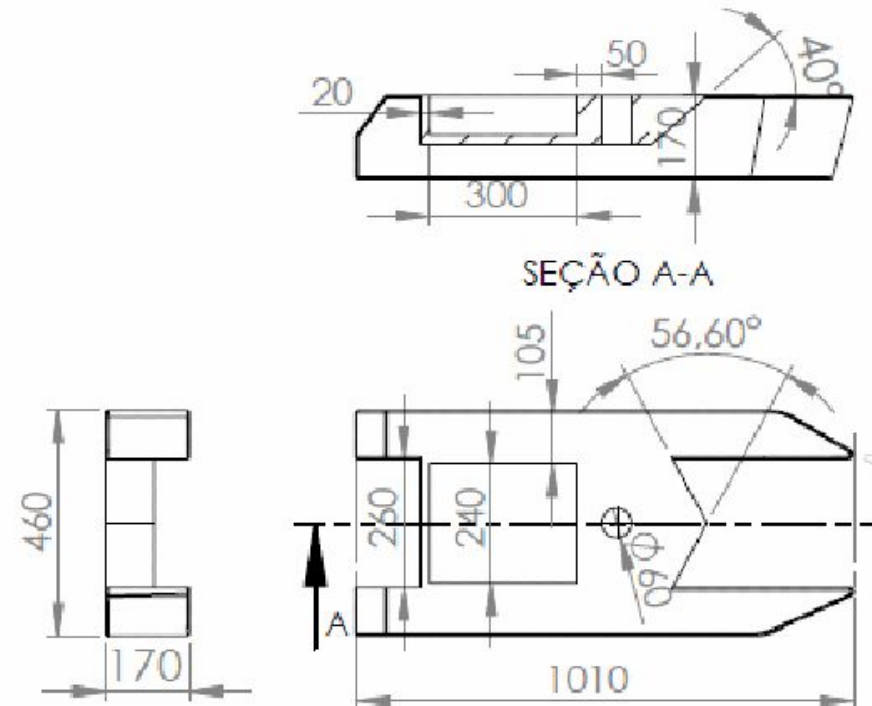

$$
\text { SEÇÃO A-A }
$$

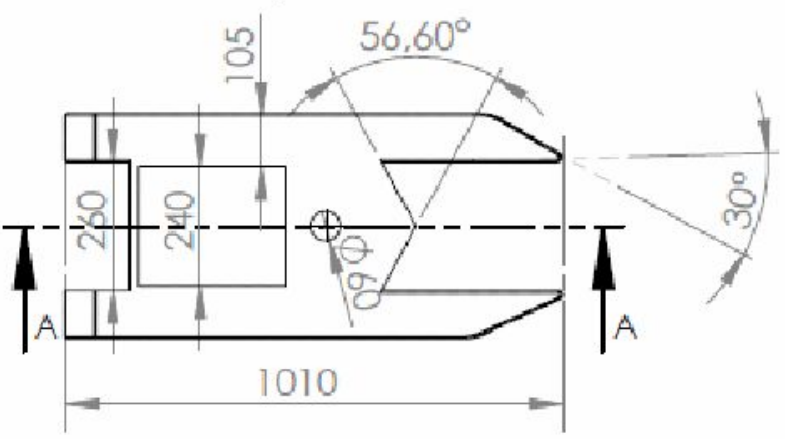

Fonte: Autores (2020)

Os materiais envolvidos no protótipo foram isopor que foi revestido com resina epóxi reforçada com fibra de vidro, próprios para ambiente aquático, a embarcação possui um metro de comprimento e 0,5 metros de largura, como mostrado na Figura 2.

FIGURA 2: A) Protótipo em isopor; B) Protótipo após revestimento.
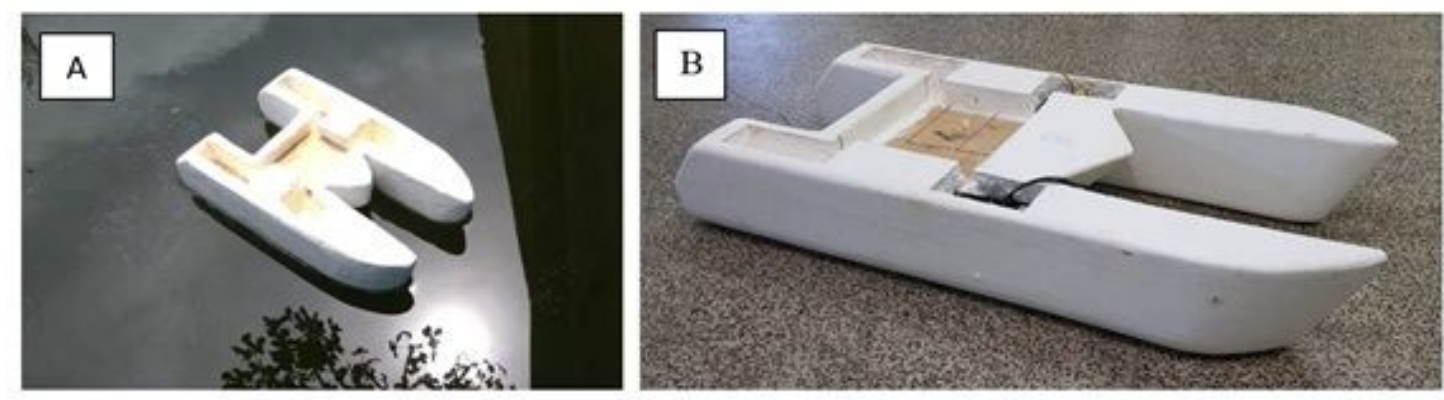

Fonte: Autores, (2020).

Uma placa de prototipagem eletrônica Arduino® Uno R3 foi utilizada como controlador central, sendo responsável por controlar os motores, além de controlar o sistema de coleta. O desenvolvimento dos algoritmos de navegação e monitoramento foi realizado no IDE do Arduino $\AA$. Foram utilizados três canais, denominados 1,3 e 4 para o estabelecimento do controle remoto. De acordo com o algoritmo, quando um desses canais é acionado, é verificado o tamanho do pulso enviado que então determina a navegação do protótipo ou o acionando o sistema de coleta das amostras de água. O fluxograma simplificado da lógica da programação utilizada pode ser visto na Figura 3. 
FIGURA 3: Fluxograma geral da programação desenvolvida.

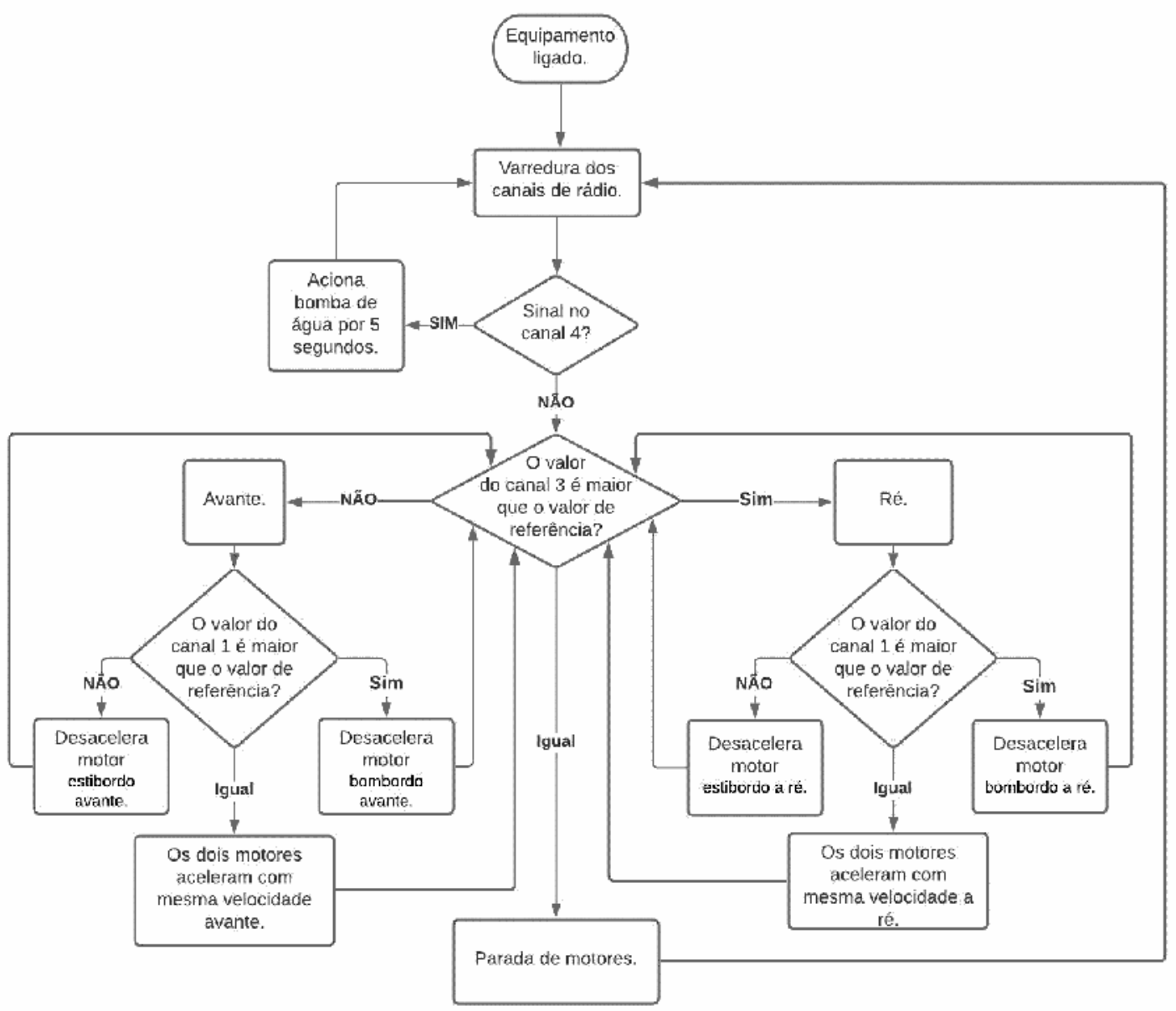

Fonte: Autores (2020)

\section{Sistema de propulsão}

Como a questão de baixo custo é um dos objetivos primários dessa pesquisa, o motor utilizado segue essa linha, sendo o motor da fabricante Ocday, modelo 3650 $4300 \mathrm{KV}$. Este modelo não possui escova, tem uma potência de 900 watts, tensão máxima 13 volts e corrente máxima de 69 amperes. O motor oferece uma rotação máxima de 50.000 RPM.

O eixo e hélices são do fabricante Feilun, eixo da hélice é do modelo FT009-11, a hélice é do modelo FT009-12. A base do sistema de propulsão é fabricada em material compensado naval para reduzir o peso, oferecendo ao mesmo tempo uma maior resistência à umidade. Com o objetivo de garantir uma maior precisão do conjunto, toda a base passou por processo de usinagem para que quatro parafusos fossem acoplados, possibilitando assim o correto alinhamento do sistema (Figura 4). 
FIGURA 4: Visão geral do sistema de propulsão: A) Base montado B) Base desmontada detalhando parafusos destinados ao alinhamento do conjunto.
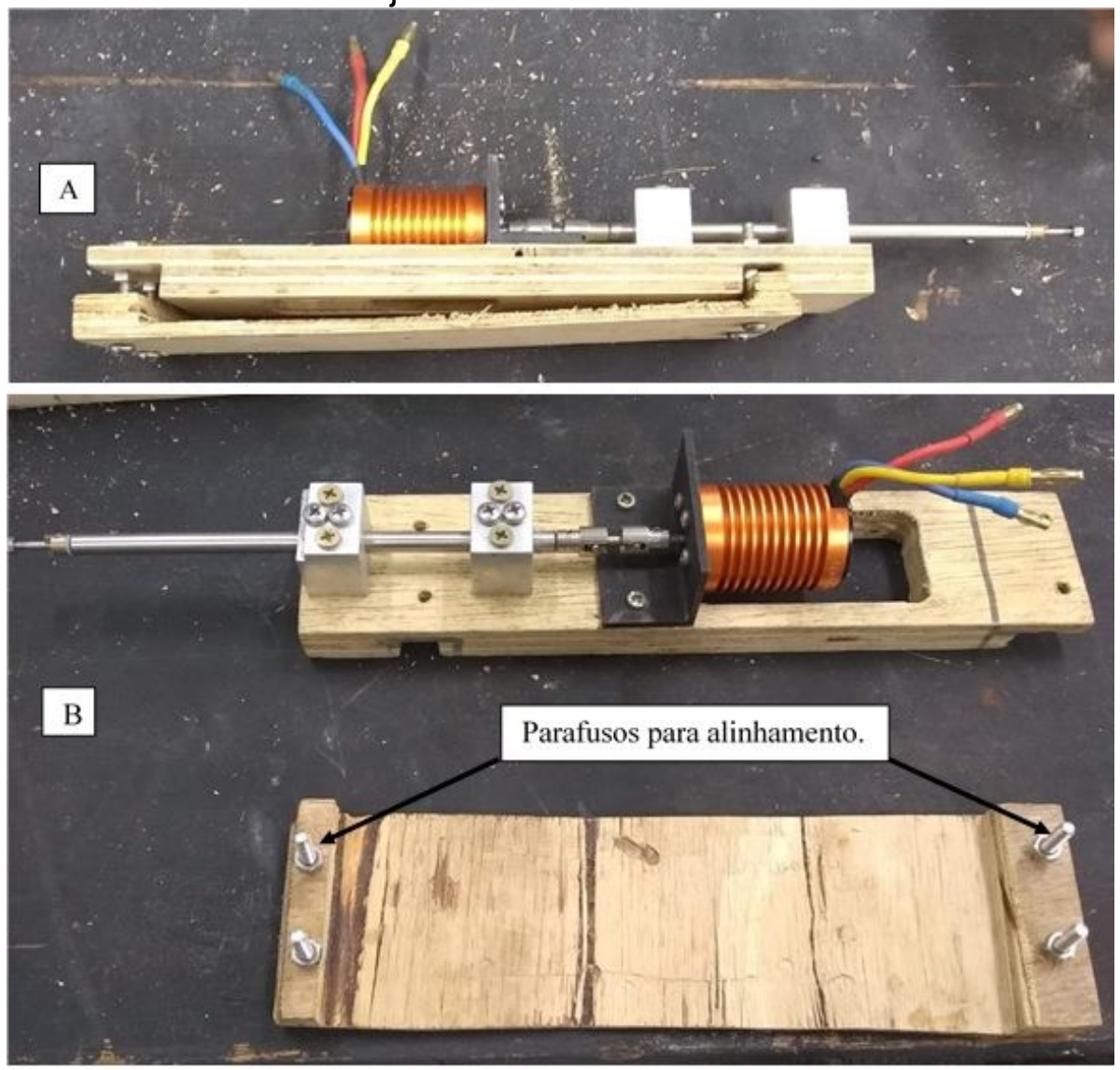

Fonte: Autores (2020)

\section{Sistema de navegação e coleta das amostras}

A comunicação entre os controladores dos motores e o receptor do rádio controle foi feita através das entradas digitais da placas prototipagem eletrônica Arduino® Uno R3. O Transmissor controle utilizado foi da marca Hobbykings modelo HK-TR6A de 2,4 $\mathrm{GHz}$ possuindo 6 canais, conforme Figura 5. 
FIGURA 5: Sistema de controle da navegação.

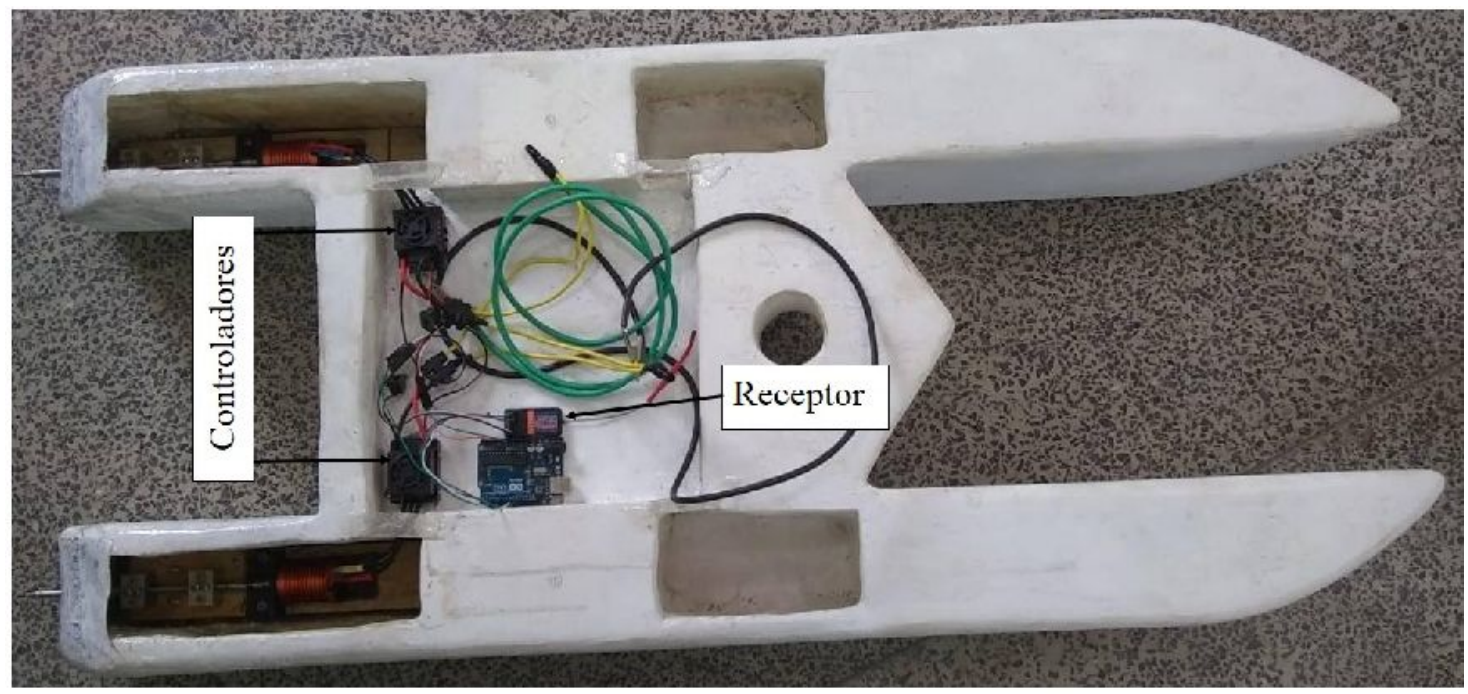

Fonte: Autores (2020).

O rádio controle utilizado foi da marca Hobbykings modelo HK-T6A 2.4Ghz, possuindo 4 canais com inversão de servo, conforme Figuras 6 .

FIGURA 6: Rádio controle utilizado no sistema de controle da navegação.

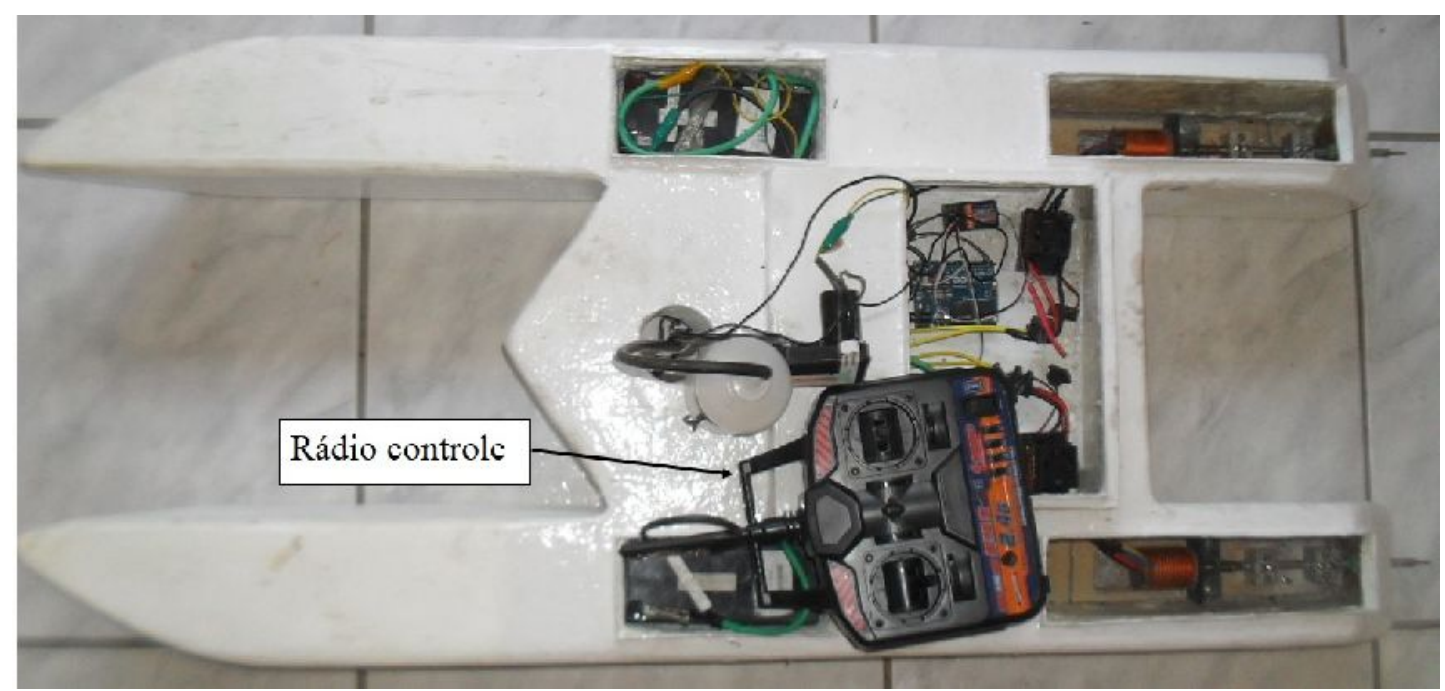

Fonte: Autores (2020).

Para a coleta de amostras de água foi usada uma Mini Bomba d'água submersa, alimentada com uma tensão de 5 volts e vazão de 1,5 litros por minuto. Esse método de amostragem é chamado de pesca elétrica sendo indicado para coleta em ambientes de águas rasas, ele evita o revolvimento do sedimento do fundo o que poderia alterar as propriedades da água (ANA, 2011). A bomba de água utilizada é mostrada na Figura 7. 
FIGURA 7: Mini Bomba de Água submersa.

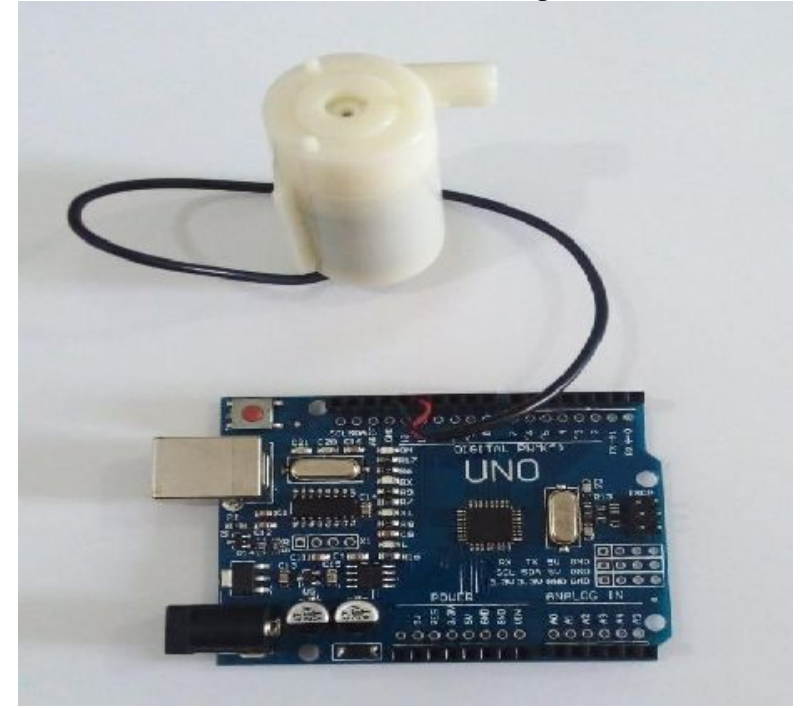

Fonte: Autores (2020)

O arrasto do sistema de coleta das amostras pode prejudicar a navegação, então um motor de passo acoplado a uma caixa redutora foi utilizado para inserir o sistema na água durante a execução da coleta (Figura 8).

FIGURA 8: Suporte do sistema de coleta: A) Erguido B) Abaixado C) Vista inferior do sistema.
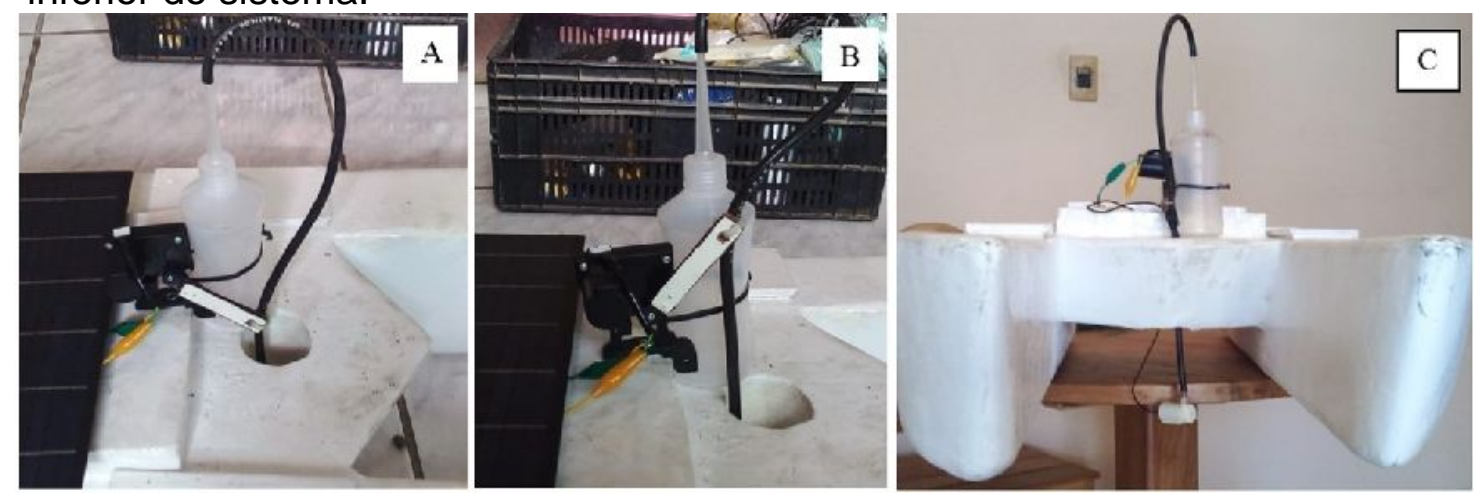

Fonte: Autores (2020).

\section{Sistema de alimentação}

O sistema de suprimento de energia escolhido para o veículo foi o sistema fotovoltaico isolado. Este sistema é composto por módulos fotovoltaicos, popularmente conhecido como placas solares, eles que realizam a transformação da energia solar em energia elétrica. As baterias foram acopladas de modo a realizar o armazenamento da energia elétrica, transformando-a em energia química. Além disso, um controlador de carga foi adicionado ao sistema, com o objetivo de fazer o gerenciamento do consumo e armazenamento de energia, determinando o envio para os componentes elétricos do veículo, como motores, sensores e atuadores (Figura 9). 
FIGURA 9: Sistema de alimentação fotovoltaico.

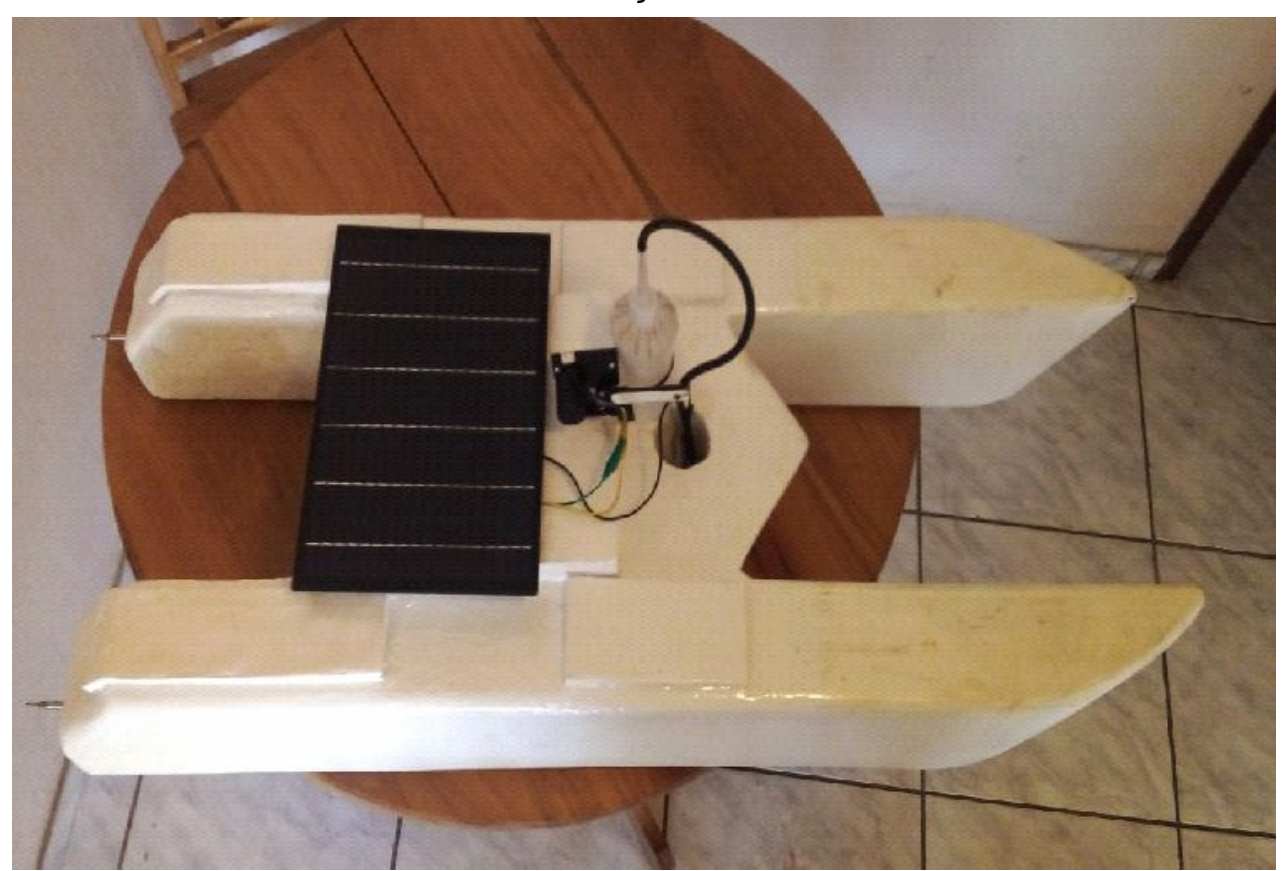

Fonte: Autores (2021).

Este estudo teve como objetivo projetar e construir um protótipo de barco robô de baixo custo, com aplicação para a atividade de monitoramento limnológico, que realizasse a coleta de amostras em corpos d'água rasos, e também avaliar a confiabilidade dos materiais utilizados na construção, além de mensurar a autonomia do sistema de suprimento de energia.

\section{RESULTADOS}

Os testes iniciais foram realizados em lago de pequenas dimensões, localizado no interior do campus do Instituto Federal Fluminense Campus Cabo Frio no estado do Rio de Janeiro, Brasil. O lago possui área aproximada de 300 metros quadrados e profundidade média de aproximadamente 1 metro.

Os testes do sistema de navegação foram realizados com o transporte de uma carga de $8 \mathrm{Kg}$ e duas baterias, com carga total de $10 \mathrm{Kg}$ de carga. O percurso realizado continha curvas e a embarcação também deve de navegar em linha reta (Figura 10). 
FIGURA 10: Registro visual das manobras com o protótipo: A) Curva à direita B) linha reta C) Curva à esquerda D) linha reta.
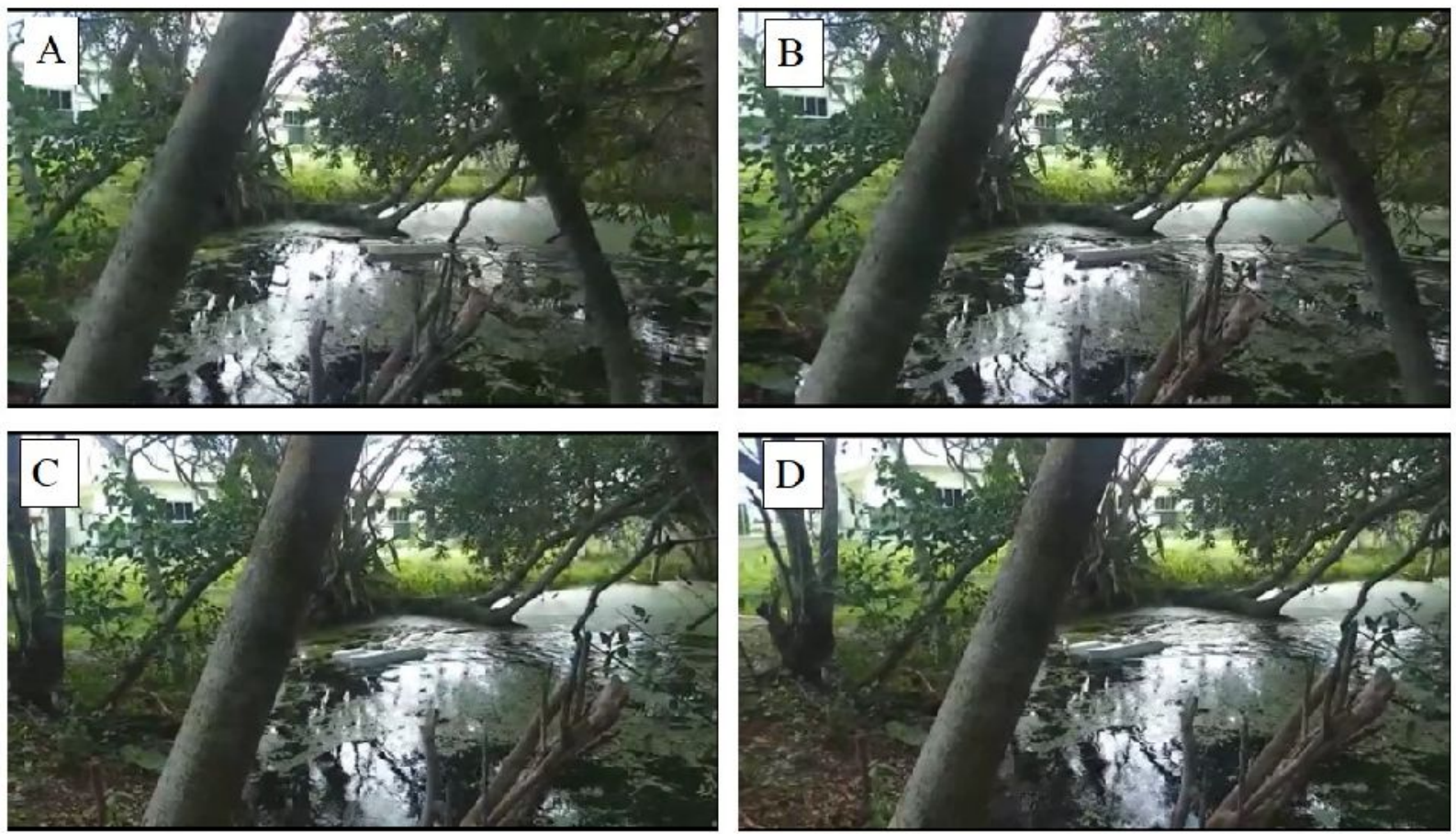

Fonte: Autores (2020).

\section{Coleta das amostras de água}

Com o barco robô em operação no lago dentro do Instituto Federal Fluminense Campus Cabo Frio, foi possível realizar o procedimento de coleta das amostras de água. A coleta foi realizada a 15 centímetros da superfície do lago, sendo coletados 250 mililitros d'água no reservatório instalado sobre o convés. As amostras coletadas foram analisadas nos laboratórios do Instituto Federal Fluminense Campus Cabo Frio. Nos testes operacionais em campo, o transmissor do rádio controle apresentou alcance como o esperado, aproximadamente 500 metros em linha reta, e o sistema de suprimento de energia manteve a embarcação funcionando ao longo de 2 horas de trabalho em ambiente com pouca incidência solar.

\section{CONCLUSÃO}

O protótipo de barco para monitoramento ambiental em águas rasas desenvolvido demonstrou ser robusto e preciso tanto para a coleta quanto para transportar as amostras d'água. A possível aplicação desse projeto em maior escala, no que concerne à sua aplicação, dimensionamento e montagem possui baixo custo. Além disso, a autonomia é satisfatória, o sistema possui baixos custos de manutenção e demonstrou ser efetivo na coleta de amostras. Assim é possível afirmar que o protótipo é promissor, com a possibilidade de aplicar melhoramentos e avanços, o que aumentaria a gama de aplicações. O acoplamento de sensores complementares de qualidade de água, por exemplo, possibilitaria mais recursos adicionando usos na embarcação. Dessa forma é possível concluir que o projeto alcançou seus objetivos ENCICLOPÉDIA BIOSFERA, Centro Científico Conhecer - Jandaia-GO, v.18 n.36; p. 126 
principais com primazia, visto que a embarcação possui baixo custo, realizando o trabalho necessário com eficiência, demonstrando seu alto valor agregado e seu essencial papel em prol monitoramento ambiental.

\section{REFERÊNCIAS}

ANA, Agência Nacional De Águas, Guia Nacional de Coletas e Preservação de Amostras, água, sedimento, comunidades aquáticas e efluentes líquidas. Brasília - DF, 2011. Disponível em: $<$ https://arquivos.ana.gov.br/institucional/sge/CEDOC/Catalogo/2012/GuiaNacionalDeC oleta.pdf>. Acesso em: 20/04/2021.

CHAVEZ, F. P.; SEVADJIAN J.; WAHL C.; FRIEDERICH J.; FRIEDERICH G. E. Measurements of $\mathrm{pCO} 2$ and $\mathrm{pH}$ from an autonomous surface vehicle in a coastal upwelling system. Deep Sea Research Part II: Topical Studies in Oceanography, v. 151, p. 137-146, 2018. DOI: https://doi.org/10.1016/j.dsr2.2017.01.001

DANTAS, J. L.; WEISS J. M.G. Revisão da metodologia de dimensionamento de hélices para embarcações fluviais. In: 9o Seminário de Transporte e Desenvolvimento Hidroviário Interior, 2015, Manaus - AM. Anais do 9 Seminário de Transporte e Desenvolvimento Hidroviário Interior, Manaus, 2015.

DOLINAY, J.; DOSTÁLEK, P.; VAŠEK, V. Arduino Debugger. IEEE Embedded Systems Letters, v. 8, n. 4, p. 85-88, 2016. DOI: 10.1109/LES.2016.2619692

ESTEVES R. A.; ROCHA J. R. S. L. Monitoramento limnológico do Rio São Francisco - RJ como ferramenta de gestão ambiental para as empresas que o utilizam como fonte de recursos hídricos. Revista Eletrônica em Gestão, Educação e Tecnologia Ambiental Santa Maria, v. 19, n. 2, p. 392-401, 2015.

FIA, R.; HUGO CÉSAR TADEU, H. C.; MENEZES J. P. C.; FIA F. R. L.; OLIVEIRA L. F. C. Qualidade da água de um ecossistema lótico urbano. Revista Brasileira de Recursos Hídricos, Porto Alegre, v. 20, n.1, p. 267 - 275, 2015. DOI: 10.21168/rbrh.v20n1.p267-275

FERREIRA, Í. O.; AYRES NETO, A.; MONTEIRO, C. S. O Uso De Embarcações Não Tripuladas Em Levantamentos Batimétricos. Revista Brasileira de Cartografia, v. 68, n. 10, 2016. Disponível em: <http://www.seer.ufu.br/index.php/revistabrasileiracartografia/article/view/44290> Acesso em: 10/05/2021.

GONZAGA S. L., LÍVIA DA SILVA OLIVEIRA L. S., ANDERSON DE OLIVEIRA CASTRO A. O. Real time energy consumption monitoring system using smart meters end arduino platform in residence. Journal of Engineering and Technology for Industrial Applications, v.5, n.19, 2019.

DOI: https://dx.doi.org/10.5935/2447-0228.20190058 
MAROTTA, H.; SANTOS R. O.; ENRICH-PRAST A. Monitoramento limnológico: um instrumento para a conservação dos recursos hídricos no planejamento e na gestão urbano-ambientais. Ambiente \& Sociedade, v.11, n.1, 2008.

DOI: https://doi.org/10.1590/S1414-753X2008000100006

STECCANELLA, L.; BLOISI, D.D.; CASTELLINI, A.; FARINELLI, A. Waterline and obstacle detection in images from low-cost autonomous boats for environmental monitoring. Robotics and Autonomous Systems, v. 124, 2020.

DOI: https://doi.org/10.1016/j.robot.2019.103346

TEIXEIRA, A. B.; RAFAEL PEREIRA, R. Construção de um equipamento de baixo custo para registro de biopotenciais cardíacos visando à análise da variabilidade da frequência cardíaca. Acta Biomedica Brasiliensia, v. 10, n. 1, 2019.

DOI: http://doi.org/10.18571/acbm.194 